\title{
Visualization Analysis of Online Health Care Research Based on Citespace
}

\author{
Siqi Yi, Shuli Gao* \\ Arts and Sciences College, Beijing Union University, Beijing, China \\ Email: ^ZDJRJCFMZTSL@163.com
}

How to cite this paper: Yi, S. Q., \& Gao, S. L. (2021). Visualization Analysis of Online Health Care Research Based on Citespace. Open Journal of Social Sciences, 9, 311-325. https://doi.org/10.4236/jss.2021.97022

Received: June 20, 2021

Accepted: July 19, 2021

Published: July 22, 2021

Copyright (อ 2021 by author(s) and Scientific Research Publishing Inc. This work is licensed under the Creative Commons Attribution International License (CC BY 4.0).

http://creativecommons.org/licenses/by/4.0/

\begin{abstract}
This article is mainly to sort out and review the field of online health care, explore the current research status of the field of online health care, reveal the research hotspots and research frontiers in this field, and provide references for other related research in the field of online health care, mainly through the following way: use citespace to visually analyze the data obtained from Web of Science. The following conclusions are drawn: The United States has strong scientific research capabilities in the field of online health care; according to citation clustering, it can be grouped into 8 research categories, and there are 8 key node documents; research hotspots can be divided into three stages, and the research front will center on knowledge, expand with quality. Starting from the Internet, online health communities, health information management, and online health education are currently research hot topics. Quality assessment and knowledge management around the above topics will be the future development direction of the online health carse field.
\end{abstract}

\section{Keywords}

Citespace, Online Health Community, Online Health Care, Visualization

\section{Introduction}

Online medical treatment, also known as online health, electronic medical treatment and telemedicine, refers to a kind of medical treatment mode that medical staff provides remote medical and health care services for patients through computer and Internet, telephone and video technology, and also refers to the electronic system supporting medical and health care services (Sims, 2018; Eland-de et al., 2011; Keogh et al., 2010). Online medical services are widely used in both developed and developing countries (Yu et al., 2016; Blaya et al., 2010). Health consumers increasingly rely on the Internet as an important source of *Corresponding author. 
health information. Jiang et al. pointed out that more than $70 \%$ of users preferred the medical solutions provided by online medical services (Jiang et al., 2020; Lee et al., 2014). The development of online medical services has brought about the enhancement of health information acquisition, sharing and discussion between patients and doctors and patients (Archer et al., 2011); health literacy, knowledge level and self-management ability of patients were improved (Shang et al., 2019). Online medical also reduces medical costs, improves the quality and efficiency of medical services, eases the tension between medical supply and demand, and solves the aging population (Jiang et al., 2020; Ross et al., 2016); efficient and high-quality collection of patient data, logistics management of auxiliary medical institutions (Blaya et al., 2010) and many other benefits. According to the survey results of the medical market innovation center (Lewis et al., 2012), in many low-income and middle-income countries, $42 \%$ use e-health to expand the geographical coverage of health care, $38 \%$ use it to improve data management, $31 \%$ use it to promote communication between patients and doctors outside the doctor's office, and other functions include improving diagnosis and treatment (17\%), reducing fraud and abuse (8\%), etc. Scholars not only study the role of online health, but also care about the implementation of e-health. Wilson and Maeder, 2015 Studied the new ideas and new development breadth in the field of telemedicine, and believed that the two main driving factors for the development of contemporary telemedicine are the large demand for specific clinical services and the high demand for clinical expertise to provide services. However, Mair et al. (Mair et al., 2012) reviewed the literature on the implementation of e-health, and considered that the research on understanding e-health system, clarifying its purpose and benefits, determining its value to users, planning its implementation, promoting or restraining the factors involved in e-health, and risk management of e-health was relatively insufficient. Similarly, Kiberu et al. (Kiberu et al., 2017) reviewed the implementation of e-health and mobile health care in Uganda, and pointed out that e-health and mobile health care in Uganda are lack of sustainability and prior planning. There are obstacles and driving forces in the implementation of e-health. In the development of e-health, some scholars are concerned about people's behavior of using e-health. For example, Ong et al. (Ong et al., 2018) studied the behavior of community pharmacists using the Internet to obtain health information, and found that the top three health information they searched most often were drug information, general health information and disease-related information. Scholars' research on e-health has also extended to the field of medical education. Kim and others (Kim et al., 2019) have developed a network-based continuing health education course for community nurses, and proved that their online continuing health education plan and course can improve nurses' ability. It can be seen that the research on online medical health has become a research topic of widespread concern, and the research field has gradually expanded. Therefore, it is necessary to sort out the current development of online health care. This paper uses visualization tools to reveal the development rules and research 
hotspots in the field of online health care from the aspects of national institutional cooperation, citation co-citation, keyword co-occurrence and keyword outburst.

\section{Data Sources and Research Methods}

\subsection{Data Sources}

Using "online health" and "online medical" as the key words, the search was carried out in the web of science core collection database. The search found that the research achievements in the field of online health care increased gradually since 2009, so the search time was determined from January 2009 to January 2020. The last search date was January 25, 2021 and 8127 related articles were retrieved.

\subsection{Research Methods}

In this paper, Citespace software is used to analyze and reveal the research status and hotspots in the field of online health care. Citespace is a scientific literature analysis tool jointly developed by Dr. Chen Chaomei of School of information science and technology of Redsell University and wise Laboratory of Dalian University of technology. It can conduct quantitative analysis of literature in specific fields, and explore the key path and knowledge turning point of discipline development. The literature data obtained in this paper includes the title, author, title, abstract, keywords and citation of each literature. Citespace software is used to cluster and analyze the above data, and to draw the co-occurrence map of national institutions, co-occurrence map of citations, co-word map of keywords and outbreak map of keywords in the field of online health care. The cooperative co-occurrence map of national institutions can explore the social relationship between national institutions in the field of online health care, and evaluate the academic influence of the state and academic institutions; The citation co-occurrence map can analyze the key nodes in the field of online health care, the evolution of topics and the historical span of literature; Keyword co-word map combined with keyword explosion map is more conducive to the research of hotspots in online health care field and the evolution of hotspots. In this paper, top 10 is selected as the data filtering strategy, that is, the top 10 high frequency nodes in each time zone are selected; MST is used to simplify the atlas and highlight the important structural features of the network. Through the process of creating matrix, dimension reduction and clustering in the background of CiteSpace software, this paper explores the research hotspots and their evolution in the field of online health care.

\section{Visual Atlas Analysis}

Firstly, this paper shows the development trend of online health care as a whole by studying the number of literature published in the field of online health care; Secondly, explore the cooperation of national institutions in the field of online health care, and reveal the distribution of academic authority in this field; Then, 
by drawing the time zone map of citation co-occurrence in this field, the research categories and key research points in the field of online health care are divided from the content, and the historical evolution process of its research topic is explored; Finally, we draw the keyword co-occurrence map and keyword outburst map to show the changes of research hotspots in the field of online health care from the perspective of keywords, and predict the future research direction in this field.

\subsection{Quantitative Analysis of Literature Publication}

In the WOS database, the number of articles published in the field of online health care has been on the rise from 2009 to 2020 (Figure 1). From 2009 to 2017, the number of published papers increased steadily, and the number of annual papers was less than 100 . The research topics in this period mainly include online health community, online medical education, epidemiology, etc. From 2017 to 2020, the number of papers published has increased sharply, with an annual increase of more than 200 papers. Since the collected data does not cover the literature in 2021, the peak growth of literature in the field of online health care is 1264 in 2020 . With the popularity of the Internet, people pay more and more attention to health, and the research achievements in the field of online health care will continue to grow in the future.

\subsection{Analysis of National Cooperation}

1) In the field of online health care, the number of articles published in the United States is the first (Figure 2), and the size of the country node represents the number of articles published. There are 2850 articles published in the United States. It was followed by Britain, Australia and Canada, with 728,602 and 527 papers in turn. Chinese mainland's distribution volume is slightly different from that of the first four countries, ranking fifth in the number of 363 articles.

2) From the perspective of cooperation, the cooperation between European countries and Commonwealth countries is relatively close, the international cooperation among American scholars is relatively less, and China has cooperation

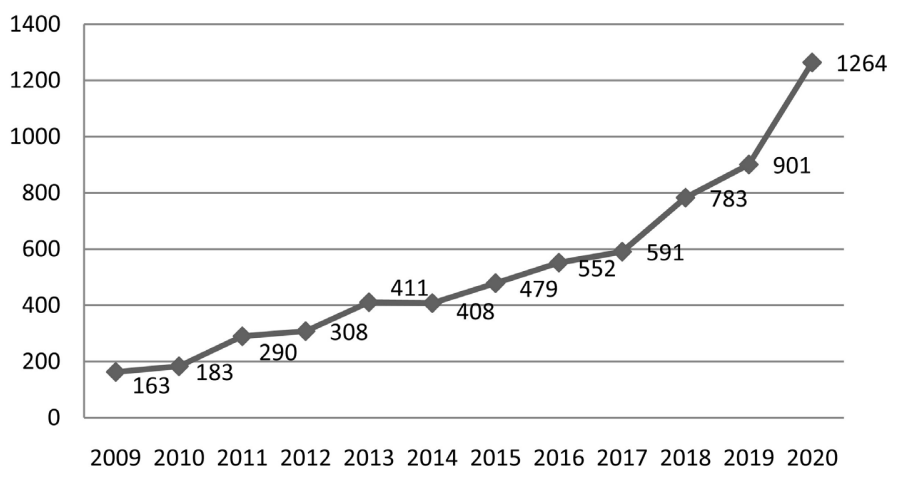

Figure 1. The number of papers published in wos in the field of online health care from 2009 to 2020 . 


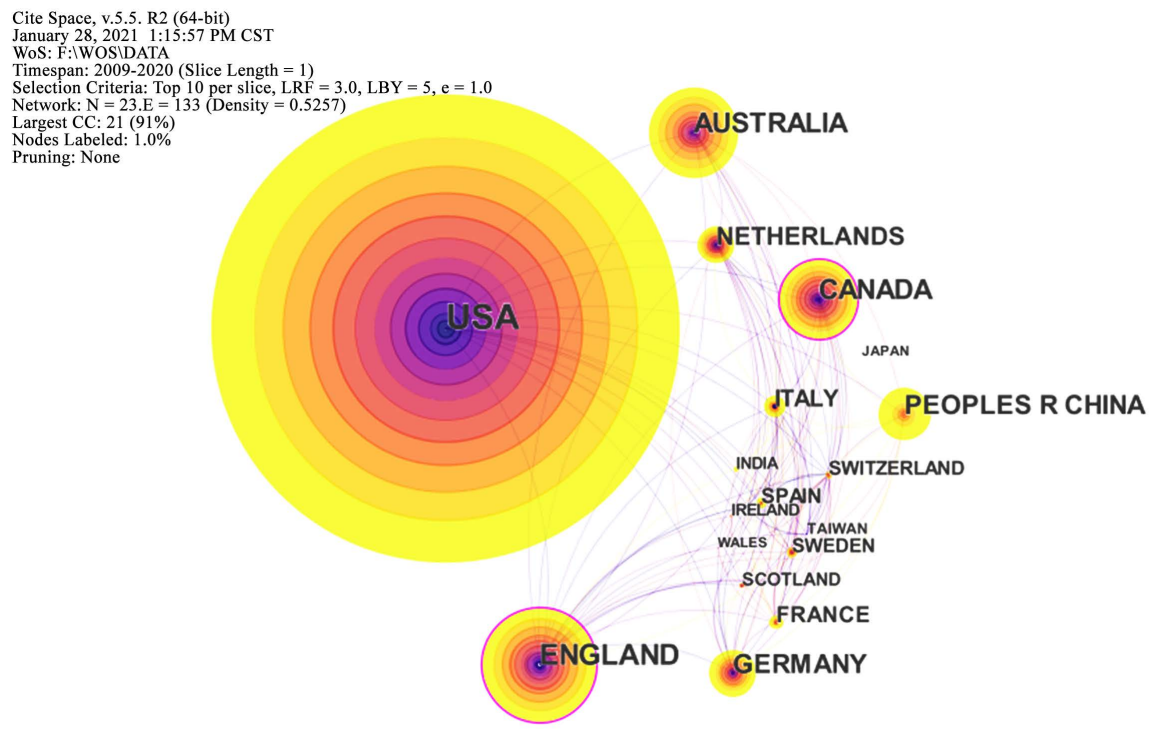

Figure 2. National cooperation in the field of online health care.

with European countries and Singapore. Canada, the United Kingdom and the Netherlands ranked the top three in terms of intermediary centrality of inter country cooperation, while the United States ranked fifth with 0.06 in terms of intermediary centrality. Moreover, the centrality of Canada and the United Kingdom is greater than 0.1 , and the nodes of the two countries are the focus of the cooperation network. This shows that Canada and the United Kingdom play a bridge role in the research cooperation among countries, and cooperate closely with other countries, while the United States has relatively little foreign cooperation.

3) The research on online health care in Asian countries is later than that in European and American countries. Europe and America have been studying since 2009, and Chinese mainland scholars from 2012 and Singapore began to study in 2015 from the beginning of 2015 and India.

\subsection{Analysis on the Cooperation of Academic Institutions}

American academic institutions have the strongest research capabilities in the field of online health care (Figure 3). The top five academic institutions in this field are Harvard Med Sch, Univ Calif San Francisco, Univ Washington, Univ Sydney and Univ Toronto. The top three are in the United States. Univ Calif San Francisco, Univ Washington, Univ Toronto, Harvard Univ and Univ Michigan have a purple outer ring outside the nodes of the five research institutions, which are the focus of this field. Harvard Univ's intermediary centrality reached a maximum of 0.37 , and its publication time was mainly concentrated between 2009 and 2015, indicating that the institution played a foundational role in the early development of this field.

\subsection{Citation Co-Occurrence Cluster Analysis}

The co-occurrence of citations in the online health and medical field can form 8 


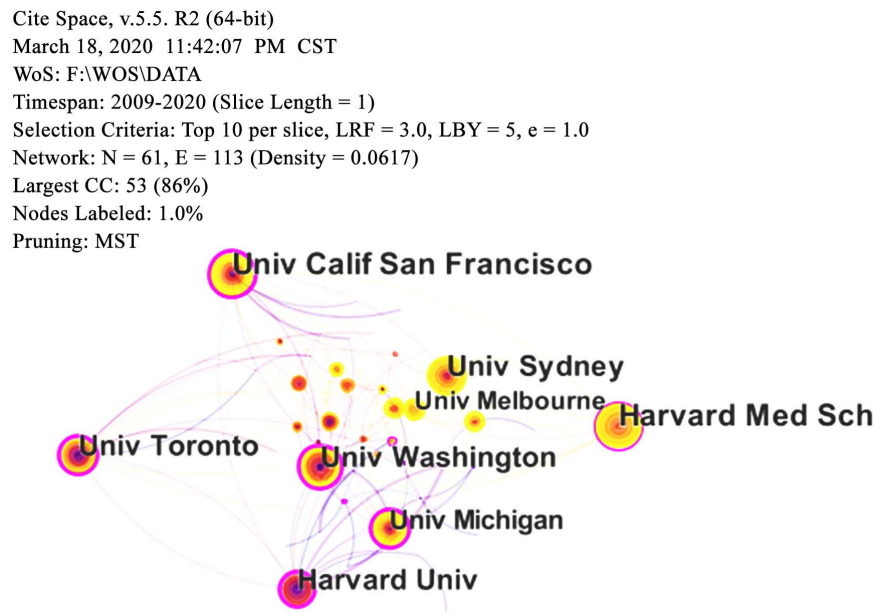

Figure 3. Cooperation diagram of institutions in the online health and medical field.

categories according to research topics. The module value $\mathrm{Q}$ value of this cluster is 0.8314 . When the $\mathrm{Q}$ value is greater than 0.3 , it can be considered that the divided categories are clear and significant. Table 1 shows the group names, keywords and main research contents of these 8 categories. Research based on Internet use has the earliest start time, and there are many connections with other categories. Research on this topic laid the foundation for other types of research; and the literature on online health communities and health information management as the research topic is mostly in the period of 2019-2020 Published. This is related to the development of the Internet, and also to the increase in health awareness of more users (Zhao, 2018), revealing to a certain extent the research development trend in the field of online health care.

\subsection{Analysis of Key Nodes of Citation Co-Occurrence}

In the document co-citation network, nodes that connect different clusters and have high centrality and citation frequency are the key nodes in the network (Chen, 2004). Figure 4 not only shows that the online health care field can be divided into eight clustering topics by topic, but also shows that there are eight highly cited key nodes in the online health care field, of which three are from online health community topics, two are from medical students topics, and the other three are from Internet application, participatory supervision and health information management topics. Among them, four key nodes (from Internet application, online health community and participatory monitoring topic) have high degree of care, and have connections with each other, which indicates that the evolution of the above three topics is closely related.

These eight key nodes reveal the trend that the research topics around the Internet, media and medical education in the field have gradually shifted to research sites such as patients and doctors in the online health care community. The specific information is shown in Table 2. 
Table 1. Citation clustering table in the field of online health care.

\begin{tabular}{|c|c|c|c|}
\hline NO. & Taxa & Keywords & Main research content \\
\hline 1 & Internet use & $\begin{array}{l}\text { Internet use, preferences, } \\
\text { trends, healthy communication }\end{array}$ & $\begin{array}{l}\text { Internet users' online health } \\
\text { information search behavior. }\end{array}$ \\
\hline 2 & $\begin{array}{l}\text { Online health } \\
\text { communities }\end{array}$ & $\begin{array}{l}\text { Doctor-patient communication, } \\
\text { knowledge cooperation, } \\
\text { caring reputation }\end{array}$ & $\begin{array}{l}\text { Doctor-patient relationship } \\
\text { in online health community. }\end{array}$ \\
\hline 3 & $\begin{array}{l}\text { Participatory } \\
\text { surveillance }\end{array}$ & $\begin{array}{l}\text { Personal health record use, } \\
\text { clinical public record, } \\
\text { medical record data }\end{array}$ & $\begin{array}{l}\text { Demographic characteristics of } \\
\text { online health care. }\end{array}$ \\
\hline 4 & Medical student & $\begin{array}{l}\text { Educational strategies, } \\
\text { continuing medical education } \\
\text { and collaborative learning }\end{array}$ & $\begin{array}{l}\text { Teaching design and teaching effect } \\
\text { of online medical education. }\end{array}$ \\
\hline 5 & Searching online & $\begin{array}{l}\text { Information quality, } \\
\text { information, release }\end{array}$ & $\begin{array}{l}\text { Content posted by users on the } \\
\text { Internet. }\end{array}$ \\
\hline 6 & $\begin{array}{l}\text { Online patient } \\
\text { resource }\end{array}$ & $\begin{array}{l}\text { Readability analysis, } \\
\text { health literacy }\end{array}$ & $\begin{array}{l}\text { Readability of online health } \\
\text { information and patient health } \\
\text { literacy. }\end{array}$ \\
\hline 7 & $\begin{array}{l}\text { Health information } \\
\text { management }\end{array}$ & $\begin{array}{l}\text { Online intervention, } \\
\text { social, media }\end{array}$ & $\begin{array}{l}\text { The influence of social media } \\
\text { on health information exchange } \\
\text { and health management. }\end{array}$ \\
\hline 8 & Patient portal & $\begin{array}{l}\text { Patient portal, access results, } \\
\text { care differences }\end{array}$ & $\begin{array}{l}\text { Usage of the online patient portal } \\
\text { and its impact on health care. }\end{array}$ \\
\hline
\end{tabular}

Table 2. Citation joint node information.

\begin{tabular}{|c|c|c|c|}
\hline NO. & Literature & $\begin{array}{c}\text { Cited } \\
\text { frequency }\end{array}$ & Centrality \\
\hline 1 & $\begin{array}{l}\text { White, R. W., Tatonetti, N. P., Shah, N. H., Altman, } \\
\text { R. B., \& Horvitz, E. (2013). Web-scale pharmacovigilance: } \\
\text { listening to signals from the crowd. Journal of the American } \\
\text { Medical Informatics Association, } 20 \text { (3), 404-408. }\end{array}$ & 23 & 0.2 \\
\hline 2 & $\begin{array}{l}\text { Tan, S. S.-L., \& Goonawardene, N. (2017). Internet Health } \\
\text { Information Seeking and the Patient-Physician Relationship: A } \\
\text { Systematic Review. Journal of Medical Internet Research, 19(1), e9. }\end{array}$ & 42 & 0.24 \\
\hline 3 & $\begin{array}{l}\text { Silver, M. P. (2015). Patient perspectives on online health } \\
\text { information and communication with doctors: a qualitative } \\
\text { study of patients } 50 \text { years old and over. Journal of } \\
\text { Medical Internet Research, } 17(1) \text {, e19. }\end{array}$ & 25 & 0.17 \\
\hline 4 & $\begin{array}{l}\text { Yang, H., Guo, X., \& Wu, T. (2015). Exploring the influence of } \\
\text { the online physician service delivery process on patient } \\
\text { satisfaction. Decision Support Systems, 78, 113-121. }\end{array}$ & 25 & 0.00 \\
\hline 5 & $\begin{array}{l}\text { Atkinson, N. L., Saperstein, S. L., \& Pleis, J. (2009). Using the } \\
\text { internet for health-related activities: findings from a national } \\
\text { probability sample. Journal of Medical Internet Research, 11 (1), e4. }\end{array}$ & 23 & 0.31 \\
\hline 6 & $\begin{array}{l}\text { Wong, G., Greenhalgh, T., \& Pawson, R. (2010). Internet-based } \\
\text { medical education: a realist review of what works, for whom and } \\
\text { in what circumstances. BMC Medical Education, } 10,12 .\end{array}$ & 27 & 0.06 \\
\hline 7 & $\begin{array}{l}\text { Cook, D. A., Erwin, P. J., \& Triola, M. M. (2010). Computerized } \\
\text { virtual patients in health professions education: a systematic } \\
\text { review and meta-analysis. Academic Medicine: Journal of the } \\
\text { Association of American Medical Colleges, } 85 \text { (10), 1589-1602. }\end{array}$ & 24 & 0.06 \\
\hline
\end{tabular}




\section{Continued}

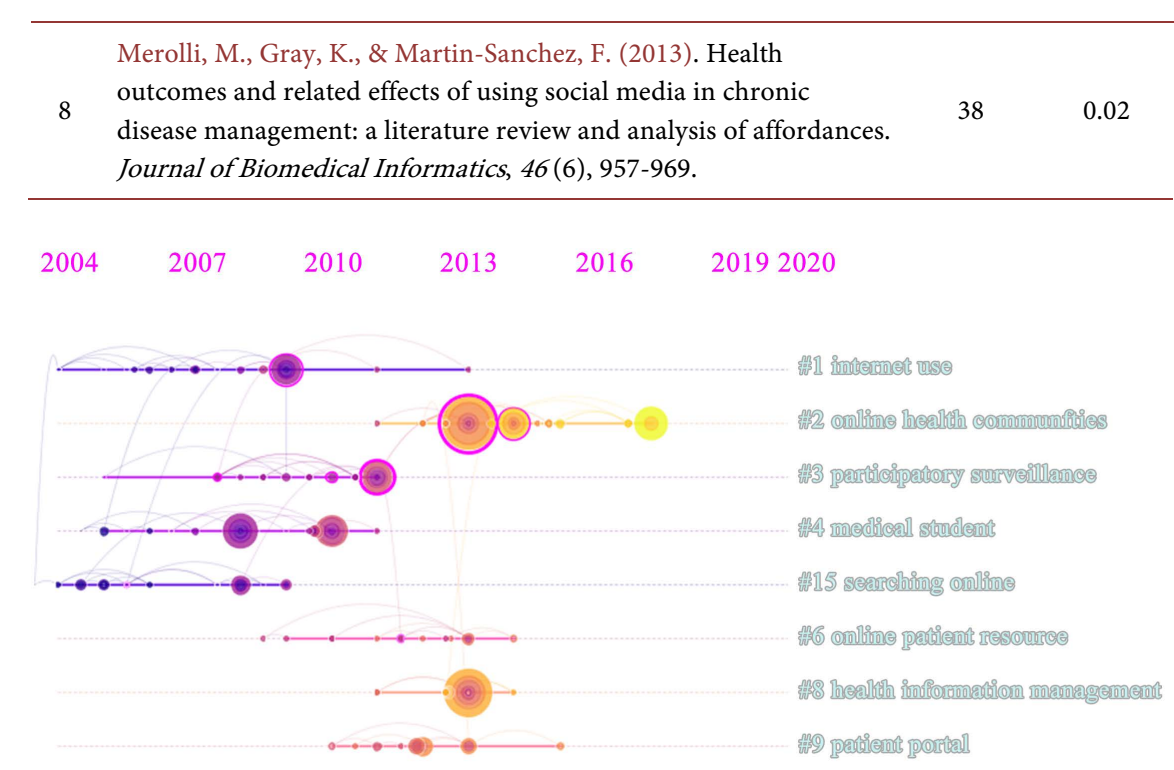

Figure 4. Timeline of co-occurrence analysis of cited documents in the online medical field.

The author of Literature 1 (White et al., 2013) took the adverse drug event that pravastatin and paroxetine can cause hyperglycemia as an example, collected Internet user online search log data before the U.S. Food and Drug Administration officially released the adverse drug event, and studied the user's attention trend has been concluded that the search activity log of the computer user group can predict the potential side effects of the drug and is helpful for the safety monitoring of the drug. In Literature 5, Atkinson et al. (Atkinson et al., 2009) conducted a multivariate analysis of the 2005 National Trends Survey of Health Information released by the National Cancer Institute, describing the demographic characteristics of online health tools. By describing and revealing the information generated by online health and medical users, these two research results help to observe the current status of online health community users and play a predictive role.

The author of Literature 4 Yang et al. (Yang et al., 2015) studied the relationship between the online doctor service provision process in the online health community and patient satisfaction, and revealed the factors that affect patient satisfaction. In literature 2 and literature 3, Tan (Tan \& Goonawardene, 2017) and Silver (Silver, 2015) both used doctor-patient communication as the theme to discuss the obstacles and facilitating factors of patients and doctors in communicating the online health information they found. Both suggested that doctors should enhance their communication skills with patients and transform the traditional doctor-patient model to adapt to the new health model of patients having Internet health information sources. In Literature 8, Merolli et al. (Merolli et al., 2013) conducted a literature review on the results and related effects of social media management of chronic diseases, explored the advantages of so- 
cial media management of chronic diseases in improving physical conditions, and suggested that tailored social media intervention programs should be developed. And further strengthen methodological research on social media management of chronic diseases.

Documents 6 and 7 both focus on online health and medical education. The author of Literature 6 (Wong et al., 2010) provides evidence-based guidance for learners and course developers to develop online medical courses. It is recommended that when designing and selecting online courses, the technical attributes and learner needs should be considered and meaningful interaction should be provided. In Literature 7, Cook et al. (Cook et al., 2010) summarized the teaching effect of using virtual patients without intervention in online medical education, using a random effect model to merge the collected teaching design and results of virtual patients in online medical education. And put forward the design features of effective virtual patients.

The above key documents have put forward many suggestions on the problems in the field of online health care, aiming to explore better development methods for this field.

\subsection{Analysis of Research Hotspots}

Keywords are high-level generalizations and summaries of the research content of the literature. This article uses the minimum generation tree pruning method to analyze the keywords and obtains three keywords with high frequency: internet, care and health. In addition to the above three high-frequency keywords, there are also keywords such as impact, attitude, mental health, risk, anxiety, depression, medical student and prevalence with a centrality greater than 0.1 . It can be seen that the Internet, health and medical care are the core of the entire field, and influence, attitude, medical education and mental health are the mainstream development directions in this field.

Table 3 shows the keywords with higher frequency and higher centrality, summarized in order of time.

Table 3. Hot keywords in the online health and medical field.

\begin{tabular}{cccccccc}
\hline Year & Frequency & Centrality & Keyword & Year & Frequency & Centrality & Keyword \\
\hline 2009 & 697 & 0.24 & Internet & 2010 & 175 & 0.26 & Prevalence \\
2009 & 660 & 0.54 & Care & 2010 & 108 & 0.17 & Risk \\
2009 & 649 & 0.50 & Health & 2011 & 221 & 0.66 & Attitude \\
2009 & 395 & 0.50 & Impact & 2016 & 131 & 0.01 & Knowledge \\
2009 & 291 & 0.03 & Education & 2019 & 129 & 0.39 & Mental health \\
2009 & 271 & 0.00 & Information & 2019 & 43 & 0.38 & Medical student \\
2009 & 237 & 0.66 & Health care & 2020 & 173 & 0.00 & Covid-19 \\
2009 & 196 & 0.09 & Physician & 2020 & 88 & 0.13 & Anxiety \\
2009 & 199 & 0.09 & Quality & 2020 & 87 & 0.26 & Depression \\
2009 & 104 & 0.03 & $\begin{array}{c}\text { Medical } \\
\text { education }\end{array}$ & & & & \\
\hline
\end{tabular}


According to the chronological order of the keywords in Table 3, the research content in the field of online health care can be divided into three stages: 2009-2010, 2010-2019, and 2019-2020, and each stage covers its main research direction.

\subsubsection{The First Stage}

2009-2010 is the first stage of development in the field of online health care. A large number of keywords with high frequency and high centrality appear in this stage, which is the foundation stage. The main research at this stage can be divided into two directions: online health communities and online medical education.

1) The main research object of the online health community is its users and its functions.

From the user's point of view, research is mainly carried out on patients and doctors. In terms of patients, the main research focuses on patient health behaviors in online health communities, patient psychology, and patient attitudes towards online health communities. Most studies concluded that the purpose of patients using online health communities is to seek information support and social support, and the interactive behaviors in online health communities can increase the frequency of patients' use. The research on the group of doctors mainly starts from the satisfaction of patients, and studies online doctors and patients, doctors' service quality and their evaluation standards, and doctors' online behaviors.

From the perspective of the main functions of the online health community, it is mainly based on the usage of the patient portal to study the demographic differences of patient portal users and construct the evaluation system of the patient portal. Most research results point out that the patient portal has widened the information gap between people with low health literacy, patients with chronic diseases, and vulnerable groups, and cannot improve the health outcomes of patients.

2) Online medical education is another research hotspot at this stage. Mainly research the teaching effect of online medical education, the way of teaching organization and the quality evaluation standard of online medical education. Studies have shown that online medical education has a significant effect, but its teaching organization methods and quality evaluation standards still need to be improved.

\subsubsection{The Second Stage}

2010-2019 is the second stage of development in the field of online health care. The research directions in this stage are relatively scattered, and no high-frequency keywords and research focus have been formed.

\subsubsection{The Third Stage}

The third development stage (2019-2020) of the online health care community is the highly prominent stage of keywords. Research in this stage focuses on inves- 
tigating the mental health of medical students and medical staff during the new crown period. Most research conclusions reflect medical students and medical staff. There are varying degrees of mental health problems during the covid-19 period.

\subsection{Research Frontier Analysis}

This article uses the built-in "Find Burst Phrases" algorithm of citespace to find the frontiers of online health care. The basic principle of this function is to use the Boolean logic function Is Hot Topic (term, $t$ ) in the knowledge base of a certain research field (mainly refer to the references of the papers in the downloaded paper data), from the knowledge base to find out hot terms in different time periods in the title, abstract, subject words and keywords of the paper. This kind of term that increases in frequency rapidly within a period of time is the research frontier term (Zhao, 2012).

Through the emergence processing of keywords, emergent words in different time periods are obtained. It can be seen from Figure 5 that the emergence of emergence words began in 2009, and the longest emergence time can be as long as five years. The three emergent words from 2016 to 2020 are the closest to the research frontier of the current field, lasting for 1 - 2 years. They are knowledge, health care and quality. Health care means health care is the main function and purpose of online health care. Knowledge and quality are the frontiers of research in the field of online health care.

1) Scholars mainly study the influencing factors of knowledge sharing and knowledge creation in online health communities and online knowledge management. For example, Yang et al. and Zhang et al. believe that personal interests, altruism, empathy, reputation and knowledge self-efficacy will promote knowledge sharing in online health communities, and the cost of knowledge sharing will hinder sharing behavior (Zhang et al., 2017; Yan et al., 2016). Zhao

et al. studied the impact of three dimensions of social capital on knowledge

Top 13 Keywords with the Strongest Citation Bursts

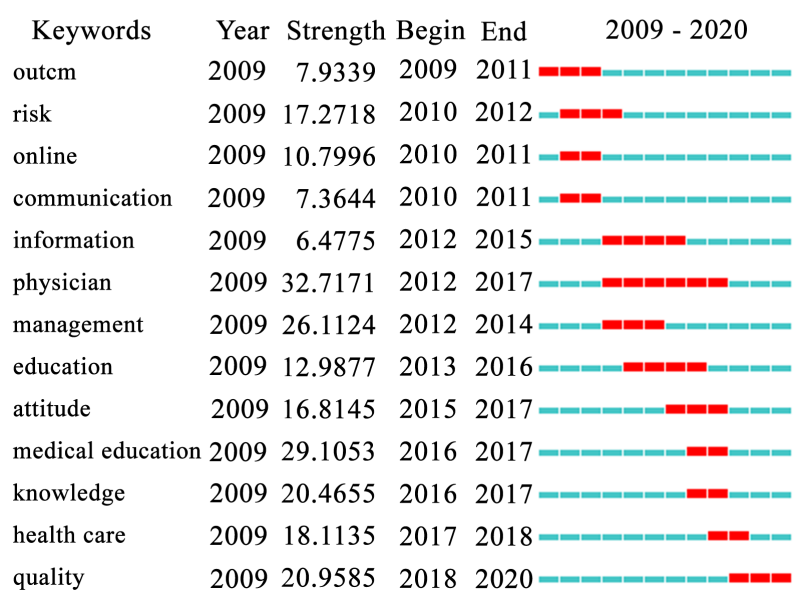

Figure 5. Keyword emergence diagram in the online medical field. 
creation in online health communities (Zhao et al., 2016). Stewart et al. believe that the knowledge map can effectively manage the knowledge in the online health community, can help determine the hot topics of users in the community, divide the areas of different shared content and customize the knowledge content for each community member (Stewart \& Abidi, 2017).

2) Research related to the emergent word "quality" mainly focuses on the evaluation of the quality of online health information, the impact of quality evaluation on patient behavior, and the evaluation of the quality of online medical education. Sun and others systematically reviewed 25 criteria and 165 indicators for evaluating online health information (Sun et al., 2019). Daraz et al. believe that the overall quality of online health information is poor (Daraz et al., 2019), and believe that differences between institutions and health professionals affect the evaluation of online health information. Battineni et al. believe that limited Internet literacy will lead to errors in the evaluation of online health information (Battineni et al., 2020). The quality rating will in turn affect patient behavior. Yaraghai et al. pointed out that patients tend to refer to government evaluations when choosing online medical institutions (Yaraghi et al., 2018). The information and service quality provided by online medical websites are positively correlated with patient satisfaction and perceived benefits (Shim \& Jo, 2020). Regarding the quality of online medicine and education, Hendricks et al. evaluated the quality of the medical MOOC education model and believed that this model is conducive to educational innovation (Hendriks et al., 2020).

\section{Conclusion}

Through citespace's national agency cooperation, citation co-occurrence, keyword co-words and emergence analysis on the online health and medical field, the following conclusions were obtained:

1) The United States has the strongest scientific research capabilities in the online health and medical field, with the most publications, and ranking top 3 academic institutions are located in the United States. The cooperation between the Commonwealth countries is closer, and the research between the United Kingdom and Canada is a bridge for cooperation between the countries. European and American countries have started research in the field of online health care earlier than Asian countries.

2) Citations in the online health and medical field can be divided into 8 categories and there are 8 key nodes. At present, scholars focus on the two categories of online health community and health information management. The key node literature reflects that scholars describe the status quo of various subjects in the online health and medical field, make suggestions for existing problems, and explore the development methods of this field.

3) Research hotspots in the field of online health care can be divided into three stages. 2009-2010 is the first stage, and the main research hotspots are online health communities and online medical education. 2010-2019 is the second stage. In this stage, research topics are scattered and no high-frequency key- 
words are formed. 2019-2020 is the third phase of this field. The main research content is the mental state of medical staff and medical students in the new crown period, which reflects the distinctive characteristics of the times. Since then, the knowledge sharing, management and creation of online health communities, the evaluation of the quality of online health information and online medical education will be the research frontiers in the field of online health care.

\section{Conflicts of Interest}

The authors declare no conflicts of interest regarding the publication of this paper.

\section{References}

Archer, N., Fevrier-Thomas, U., Lokker, C., McKibbon, K. A., \& Straus, S. E. (2011). Personal Health Records: A Scoping Review. Journal of the American Medical Informatics Association, 18, 515-522. https://doi.org/10.1136/amiajnl-2011-000105

Atkinson, N. L., Saperstein, S. L., \& Pleis, J. (2009). Using the Internet for Health-Related Activities: Findings from a National Probability Sample. Journal of Medical Internet Research, 11, Article No. e4. https://doi.org/10.2196/jmir.1129

Battineni, G., Baldoni, S., Chintalapudi, N., Sagaro, G. G., Pallotta, G., Nittari, G., \& Amenta, F. (2020). Factors Affecting the Quality and Reliability of Online Health Information. Digital Health, 6, Article ID: 2055207620948996.

https://doi.org/10.1177\%2F2055207620948996

Blaya, J. A., Fraser, H. S. F., \& Holt, B. (2010). E-Health Technologies Show Promise in Developing Countries. Health Affairs, 29, 244-251.

https://doi.org/10.1377/hlthaff.2009.0894

Chen, C. (2004). Searching for Intellectual Turning Points: Progressive Knowledge Domain Visualization. Proceedings of the National Academy of Sciences of the United States of America, 101, 5303-5310. https://doi.org/10.1073/pnas.0307513100

Cook, D. A., Erwin, P. J., \& Triola, M. M. (2010). Computerized Virtual Patients in Health Professions Education: A Systematic Review and Meta-Analysis. Academic Medicine, 85, 1589-1602. https://doi.org/10.1097/ACM.0b013e3181edfe13

Daraz, L., Morrow, A. S., Ponce, O. J., Beuschel, B., Farah, M. H., Katabi, A., Alsawas, M., Majzoub, A. M., Benkhadra, R., Seisa, M. O., Ding, J. F., Prokop, L., \& Murad, M. H. (2019). Can Patients Trust Online Health Information? A Meta-Narrative Systematic Review Addressing the Quality of Health Information on the Internet. Journal of General Internal Medicine, 34, 1884-1891. https://doi.org/10.1007/s11606-019-05109-0

Eland-de Kok, P., van Os-Medendorp, H., Vergouwe-Meijer, A., Bruijnzeel-Koomen, C., \& Ros, W. (2011). A Systematic Review of the Effects of E-Health on Chronically Ill Patients. Journal of Clinical Nursing, 20, 2997-3010. https://doi.org/10.1111/j.1365-2702.2011.03743.x

Hendriks, R. A., de Jong, P. G. M., Admiraal, W. F., \& Reinders, M. E. J. (2020). Instructional Design Quality in Medical Massive Open Online Courses for Integration into Campus Education. Medical Teacher, 42, 156-163. https://doi.org/10.1080/0142159X.2019.1665634

Jiang, J., Cameron, A.-F., \& Yang, M. (2020). Analysis of Massive Online Medical Consultation Service Data to Understand Physicians' Economic Return: Observational Data Mining Study. JMIR Medical Informatics, 8, Article No. e16765. 
https://doi.org/10.2196/16765

Keogh, E., Rosser, B. A., \& Eccleston, C. (2010). E-Health and Chronic Pain Management: Current Status and Developments. Pain, 151, 18-21. https://doi.org/10.1016/j.pain.2010.07.014

Kiberu, V. M., Mars, M., \& Scott, R. E. (2017). Barriers and Opportunities to Implementation of Sustainable E-Health Programmes in Uganda: A Literature Review. African Journal of Primary Health Care \& Family Medicine, 9, Article No. a1277. https://doi.org/10.4102/phcfm.v9i1.1277

Kim, E.-H., Kim, K.-H., \& Bae, K.-E. (2019). Development of Online Continuing Education Courses on National Health Examination for Community Health Nurses: Using the Rapid Prototyping Method. Journal of the Korea Academia-Industrial Cooperation Society, 20, 250-263. https://doi.org/10.5762/KAIS.2019.20.8.250

Lee, K., Hoti, K., Hughes, J. D., \& Emmerton, L. M. (2014). Interventions to Assist Health Consumers to Find Reliable Online Health Information: A Comprehensive Review. PLoS ONE, 9, e94186. https://doi.org/10.1371/journal.pone.0094186

Lewis, T., Synowiec, C., Lagomarsino, G., \& Schweitzer, J. (2012). E-Health in Low- and Middle-Income Countries: Findings from the Center for Health Market Innovations. Bulletin of the World Health Organization, 90, 332-340.

https://doi.org/10.2471/BLT.11.099820

Mair, S. F., May, C., O’Donnell, C., Finch, T., Sullivan, F., \& Murray, E. (2012). Factors That Promote or Inhibit the Implementation of E-Health Systems: An Explanatory Systematic Review. Bulletin of the World Health Organization, 90, 357-364. https://doi.org/10.2471/BLT.11.099424

Merolli, M., Gray, K., \& Martin-Sanchez, F. (2013). Health Outcomes and Related Effects of Using Social Media in Chronic Disease Management: A Literature Review and Analysis of Affordances. Journal of Biomedical Informatics, 46, 957-969. https://doi.org/10.1016/j.jbi.2013.04.010

Ong, S. W., Hassali, M. A., \& Saleem, F. (2018). Community Pharmacists' Perceptions towards Online Health Information in Kuala Lumpur, Malaysia. Pharmacy Practice, 16, Article No. 1166. https://doi.org/10.1186/s13012-016-0510-7

Ross, J., Stevenson, F., Lau, R., \& Murray, E. (2016). Factors That Influence the Implementation of E-Health: A Systematic Review of Systematic Reviews (An Update). Implementation Science, 11, Article No. 146.

Shang, L., Zuo, M., Ma, D., \& Yu, Q. (2019). The Antecedents and Consequences of Health Care Professional-Patient Online Interactions: Systematic Review. Journal of Medical Internet Research, 21, Article No. e13940. https://doi.org/10.2196/13940

Shim, M., \& Jo, H. S. (2020). What Quality Factors Matter in Enhancing the Perceived Benefits of Online Health Information Sites? Application of the Updated DeLone and McLean Information Systems Success Model. International Journal of Medical Informatics, 137, Article ID: 104093. https://doi.org/10.1016/j.ijmedinf.2020.104093

Silver, M. P. (2015). Patient Perspectives on Online Health Information and Communication with Doctors: A Qualitative Study of Patients 50 Years Old and Over. Journal of Medical Internet Research, 17, Article No. e19. https://doi.org/10.2196/jmir.3588

Sims, J. M. (2018). Communities of Practice: Telemedicine and Online Medical Communities. Technological Forecasting \& Social Change, 126, 53-63.

https://doi.org/10.1016/j.techfore.2016.08.030

https://kns-cnki-net-443.webvpn.buu.edu.cn/kcms/detail/detail.aspx?FileName=SJESA 1231E23BE42155068A0D8A45D72DA81\&DbName=SJES2018

Stewart, S. A., \& Abidi, S. S. R. (2017). Leveraging Medical Taxonomies to Improve 
Knowledge Management within Online Communities of Practice: The Knowledge Maps System. Computer Methods and Programs in Biomedicine, 143, 121-127. https://doi.org/10.1016/j.cmpb.2017.03.003

Sun, Y., Zhang, Y., Gwizdka, J., \& Trace, C. B. (2019). Consumer Evaluation of the Quality of Online Health Information: Systematic Literature Review of Relevant Criteria and Indicators. Journal of Medical Internet Research, 21, Article No. e12522. https://doi.org/10.2196/12522

Tan, S. S.-L., \& Goonawardene, N. (2017). Internet Health Information Seeking and the Patient-Physician Relationship: A Systematic Review. Journal of Medical Internet Research, 19, Article No. e9. https://doi.org/10.2196/jmir.5729

White, R. W., Tatonetti, N. P., Shah, N. H., Altman, R. B., \& Horvitz, E. (2013). Web-Scale Pharmacovigilance: Listening to Signals from the Crowd. Journal of the American Medical Informatics Association, 20, 404-408. https://doi.org/10.1136/amiajnl-2012-001482

Wilson, L. S., \& Maeder, A. J. (2015). Recent Directions in Telemedicine: Review of Trends in Research and Practice. Healthcare Informatics Research, 21, 213-222. https://doi.org/10.4258/hir.2015.21.4.213

Wong, G., Greenhalgh, T., \& Pawson, R. (2010). Internet-Based Medical Education: A Realist Review of What Works, for Whom and in What Circumstances. BMC Medical Education, 10, Article No. 12. https://doi.org/10.1186/1472-6920-10-12

Yan, Z., Wang, T., Chen, Y., \& Zhang, H. (2016). Knowledge Sharing in Online Health Communities: A Social Exchange Theory Perspective. Information \& Management, 53, 643-653. https://doi.org/10.1016/j.im.2016.02.001

Yang, H., Guo, X., \& Wu, T. (2015). Exploring the Influence of the Online Physician Service Delivery Process on Patient Satisfaction. Decision Support Systems, 78, 113-121. https://doi.org/10.1016/j.dss.2015.05.006

Yaraghi, N., Wang, W., Gao, G. G., \& Agarwal, R. (2018). How Online Quality Ratings Influence Patients' Choice of Medical Providers: Controlled Experimental Survey Study. Journal of Medical Internet Research, 20, Article No. e99. https://doi.org/10.2196/jmir.8986

Yu, J., Huang, X., \& Dong, K. (2016). A Survey of Online Medical Research Based on Knowledge Graph. Journal of Information Resources Management, No. 2, 4-12+21. https://kns-cnki-net-443.webvpn.buu.edu.cn/kcms/detail/detail.aspx?FileName=XNZY $201602001 \&$ DbName $=$ CJFQ2016

Zhang, X., Liu, S., Deng, Z., \& Chen, X. (2017). Knowledge Sharing Motivations in Online Health Communities: A Comparative Study of Health Professionals and Normal Users. Computers in Human Behavior, 75, 797-810. https://doi.org/10.1016/j.chb.2017.06.028

Zhao, D. Q. (2012). Discussion on Several Issues of Scientific Knowledge Graph Drawing Based on Citespace. Information Theory and Practice, No. 10, 56-58.

https://kns-cnki-net-443.webvpn.buu.edu.cn/kcms/detail/detail.aspx?FileName=QBLL 201210012\&DbName $=$ CJFQ2012

Zhao, D. X. (2018). A Review of the Research Status of Domestic Online Health Communities. Library and Information Work, No. 9, 134-142.

https://kns-cnki-net-443.webvpn.buu.edu.cn/kcms/detail/detail.aspx?FileName=TSQB 201809022\&DbName $=$ DKFX2018

Zhao, J., Ha, S., \& Widdows, R. (2016). The Influence of Social Capital on Knowledge Creation in Online Health Communities. Information Technology \& Management, 17, 311-321. https://doi.org/10.1007/s10799-014-0211-3 